\title{
Antibacterial effect of polyphenols extracted from different honeys against methicillin-resistant staphylococcus aureus
}

\begin{abstract}
Title: Antibacterial Effect of Polyphenols Extracted from Different Honeys against MethicillinResistant Staphylococcus aureus.

Background: Methicillin resistant Staphylococcus aureus present multiple problems of nosocomial infectious diseases, in addition to the multidrug resistance. Our work aims to evaluate the antibacterial effect of four polyphenolic extracts from honey against Methicillin resistant Staphylococcus aureus.

Methods and findings: An extraction of polyphenol was carried out from different honey samples collected from different sites of the Algerian territory. Then, the study of the antibacterial effect was performed by the determination of inhibition diameter and the minimal inhibitory concentration. The results indicated that the extracts of honey presented different total phenolic content with high value of $76 \pm 1.1 \mathrm{mg} \mathrm{GAE} / 100 \mathrm{~g}$ of fresh weight. It was clearly showed the sensitivity of MRSA against polyphenolic extracts. This inhibitory effect was found for the four samples tested with varying degrees of inhibition. The polyphenolic extract of Jijel has the highest inhibitory effect among all extracts with the MIC of $0.095 \mu \mathrm{l} / \mathrm{ml}$.
\end{abstract}

Conclusions: The study of the antibacterial effect of honey extracts allowed us to present an alternative way against the infectious diseases.

Keywords: Antibioresistance - Polyphenols - Staphylococcus aureus " Honey

Submitted: 11 January 2017; Accepted: 30 January 2017; Published online: 20 February 2017

\section{Introduction}

Staphylococcus aureus is a bacterium of significant importance because of its ability to cause a wide range of diseases and capacity to adapt to diverse environmental forms $[1,2]$. The organism colonizes skin, skin glands and mucous membrane, causing infections both in human and animals such as rashes, inflammations of bones and the meninges as well as septicaemia [3].
Penicillin and its derivatives, including methicillin have been used for the treatments of infections caused by $S$. aureus [4]. However, certain strains of $S$. aureus developed resistance known as methicillin resistant Staphylococcus aureus (MRSA). At a time when modern medicine is faced with various problems (antibiotic resistance, increased health care costs ...), said natural therapeutic attracting renewed interest.
Belkhodja $\mathrm{H}^{*}$, Belmimoun $\mathrm{A}$ and Meddah B

Laboratory of Bioconversion, Microbiology Engineering and Health Safety, Department of Biology, University of Mascara, Algeria

*Author for correspondence: hamzabelkhodja@yahoo.fr 
The bioactive compounds in honey present a valuable supplement for healthy population [5]. Many scientific studies will show the many virtues of honey based on their properties (antibacterial, antifungal and antiviral) on nutritionally than the therapeutic level. Recent advances in research, literature highlighted that honey has potential biological activities with promising health promoting properties [6].

Research indicates that honey has functional properties in human health promotion that depend largely on the floral source. These properties could be associated to honey high osmolarity, antibacterial properties [7] and antioxidant capacity [8]. Honey has an established function as an antibacterial agent that has a broad spectrum of activity against Gram positive and Gram negative bacteria [9]. Large number of honeys from different geographical locations and different botanical origins show growth inhibitory action. Honey, given its multiple properties, deserves more attention from the medical profession. Its low cost makes it an ideal therapeutic both in developing countries where the drugs are starved than in developed countries where health economies have become the watchword. It is time to rediscover the virtues of honey [10].

Viewing these therapeutic activities of honey, our work aims to evaluate the antibacterial effect of four polyphenolic extracts from honey against Methicillin resistant Staphylococcus aureus.

\section{Materials and Methods \\ Biological material}

The sample consists of four types of honey: Tlemcen, Oran, Jijel and Mascara. The four Algerian cities were characterized by a Mediterranean climate but Mascara is Mediterranean with a tendency to semi-arid. The four harvested honeys were canned in sealed glass bottles. For the study of the antibacterial effect, the chosen species was Methicillin resistant Staphylococcus aureus isolated from a patient (male, 27 years) with an anal fistula.

\section{Extraction of phenolic compounds from honey}

A quantity of honey was mixed with hydrochloric acid and Sodium metabisulfite. Then, the mixture was hydrolyzed with ethanol-water. It was followed by stirring for $5 \mathrm{~min}$ and filtration. Final step of rotary evaporator was performed at $40^{\circ} \mathrm{C}$ to obtain the polyphenol extract. The extract was conserved after yield calculating [11].

\section{Total phenolic content (TPC)}

The dosage of total phenolic content was made using the reactive Folin-Ciocalteau [12]. Briefly, 5
$\mathrm{mL}$ of aqueous eluate of honey $(0.5 \mathrm{~g}$ honey $/ 50 \mathrm{~mL}$ of distilled water) was added to $0.5 \mathrm{~mL}$ of Folin-Ciocalteu (FC) reagent and $1.5 \mathrm{~mL} 20 \% \mathrm{Na}_{2} \mathrm{CO}_{3}$ solution. After agitation, the reaction mixture was left to stand for $120 \mathrm{~min}$ and then measured by spectrophotometer UV-visible of double beam type SHIMADZU UV$2401 \mathrm{PC}$ at $\mathrm{k}=760 \mathrm{~nm}$ against the blank (water). To ensure that the results are reliable, the dosage of each phenolic compound was carried out in three trials. The use of a standard range was established under the same conditions with Gallic acid (0 to $1 \mathrm{~g} / \mathrm{l}$ ). The TPC was expressed in $\mathrm{mg}$ of gallic acid equivalents (GAE)/100 g (Sekou et al. 2009).

\section{Effect of polyphenolic extracts on MRSA strain}

The evaluation of the antibacterial activity of honey was on a standard, economical and rapid method. This method was based on the migration to extract inside a Petri dish in a solid nutrient medium. The culture medium used was the Muller-Hinton agar $(4 \mathrm{~mm})$ [13]. Seeding $1 \mathrm{ml}$ of inoculum calibrated at $0.5 \mathrm{Mc}$ Farland was done by swabbing the surface after the solidification of the medium. Disks prepared with Whatman paper (No. 03) were soaked with a volume of extract dilutions (60\%, 70\%, 80\%, 90\% and 100\%). The disks were then deposited on the surface of MullerHinton agar by pressing lightly with a sterile forceps. The choice of dilution has been taken into account as a result of preliminary tests.

\section{MIC determination by the dilution method}

Into a series of tubes, $9 \mathrm{ml}$ of Muller-Hinton liquid medium was dispensed. These tubes were then inoculated with $0.1 \mathrm{ml}$ of bacterial suspension calibrated then added increasing concentrations of polyphenolic extract $(1 / 2,1 / 4,1 / 8,1 / 16)$. A control tube without extract was used. After incubation at $37^{\circ} \mathrm{C}$, the tubes were carefully examined and the optical density was denoted [14].

\section{Results and Discussion}

Yields of phenolic extracts

Each sample of honey has recovered a precise amount of polyphenolic extract. The quantities obtained were listed in Table 1.

The extracts of honey presented a different value of

\begin{tabular}{|c|c|c|c|}
\hline Samples & Coloring & Aspect & Yield (\%) \\
\hline Jijel & Brown & Viscous & $18.5 \pm 0.11 \%$ \\
\hline Oran & Brown & Viscous & $20 \pm 0.22 \%$ \\
\hline Tlemcen & Yellow & Liquid & $13 \pm 0.6 \%$ \\
\hline Mascara & Yellow & Liquid & $20.2 \pm 0.2 \%$ \\
\hline
\end{tabular}


yields. The high yield was indicated in the extract of Mascara honey with $20.2 \pm 0.2 \%$. Honey color depends on various factors, such as their mineral content. It has been previously reported by (Al et al. 2009) and (Gomes et al. 2010) that light-colored honeys usually have low ash content, while dark-colored honeys generally have higher ash content $[15,16]$.

\section{Total phenolic content (TPC)}

After preparing the calibration range of Gallic acid $(0.25 \mathrm{~g} / \mathrm{l}, 0.5 \mathrm{~g} / \mathrm{l}, 0.75 \mathrm{~g} / \mathrm{l}, \mathrm{g} / \mathrm{l})$, the measurement of the optical density was performed at wave length 760 $\mathrm{nm}$. The calibration curve obtained showed the linearity of the detector response as a function of different concentrations (Figure 1). The mean absorbance of extracts of honey (Jijel, Mascara, Oran, and Tlemcen) was showed in Table 2.

Table 2. Optical densities of polyphenolic extracts of honey.

\begin{tabular}{|lcccc|}
\hline Extract & Jijel & Oran & Mascara & Tlemcen \\
\hline Optical density (OD) & 0.721 & 0.401 & 0.286 & 0.360 \\
\hline
\end{tabular}

The concentration of each extract was obtained by projection of the average absorbance of the calibration curve. The TPC of the different honeys was investigated by the Folin-Ciocalteu assay and the mean values and standard deviation are shown in (Figure 2). It was observed that the TPC showed significant differences between the different honeys samples. According to these results, the honey of Jijel had the highest TPC values $(76 \pm 1.1 \mathrm{mg}$ GAE $/ 100 \mathrm{~g}$ of fresh weight), while the lowest content was measured in the honey of Mascara (32.6 $\pm 0.9 \mathrm{mg} \mathrm{GAE} / 100 \mathrm{~g}$ of fresh weight). This large difference was probably due to the storage conditions of the original honey and from the different solids content of honey. The total content of phenols in honey was highly dependent its plant source. The literature data indicate that total phenolic content is very diverse and ranges from $0.5 \mathrm{mg} / 100 \mathrm{~g}$ to 130.0 $\mathrm{mg} / 100 \mathrm{~g}$ of honey [17].

According to Harris, these different levels of phenolic compounds between the different extracts of honey were the result of the effect of a number of

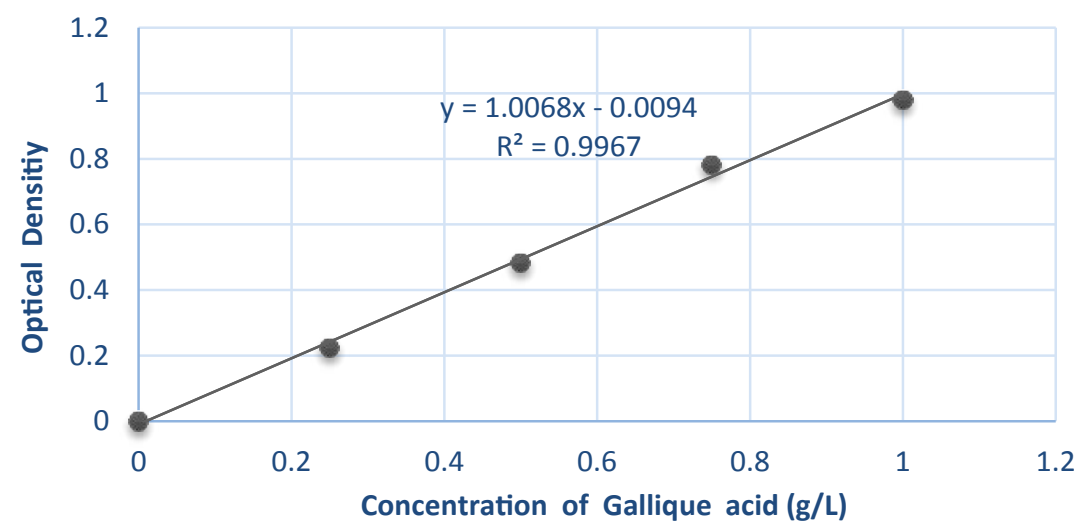

Figure 1. Calibration curve for the determination of total phenolic compounds

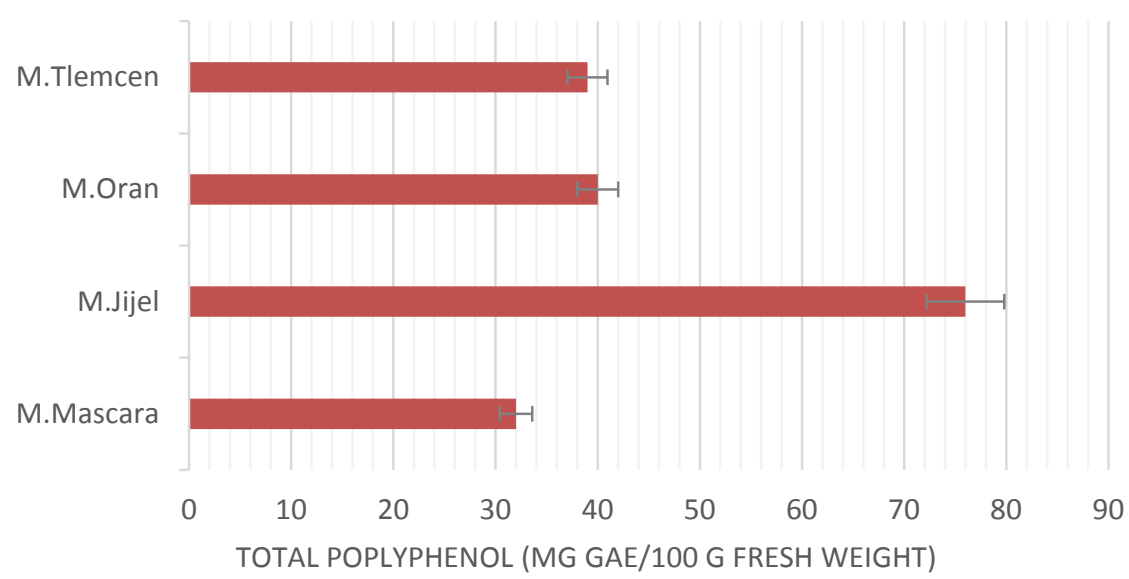

Figure 2. Rate of polyphenols of different honeys 
influential factors on the honeys: light, precipitation, the rate of Hydroxymethylfurfural (HMF) and season [18]. In this regard, Macheix et al. reported that the concentration of polyphenols varied from one variety to another and declined steadily during ripening and storage [19]. This variation was based on several factors including temperature, $\mathrm{pH}$ and the quantitative and qualitative changes in phenolic compounds contained in the original plants [20].

\section{Effect of polyphenolic extracts against MRSA}

According to our results, it was found that the growth of the strain studied "MRSA" was low around the majority of impregnated disks. The absence of growth was indicated by inhibition zones with different diameters (Figure 3). This difference in diameter may be due to the difference of the charge and the concentration of each disk on polyphenolic extract.

It was noted a high resistance of MRSA against the extract of Mascara for the concentration of $60 \%$. Whereas the high sensitivity was recorded for the extract of Jijel especially for the concentration of $100 \%$ with inhibition diameter of $40 \mathrm{~mm}$. The antimicrobial capacity of phenolic compounds is well known [21] and, as previously described by [22], individual phenolic compounds present in honey show important antibacterial activity. Our results agreed with the data observed [23]. They also observed that $S$. aureus was the most sensitive bacteria to honey compounds.

In our study, the activity of the extracts was due to the polyphenols and it could therefore be related to the degree of oxidation of these compounds. Indeed, polyphenols were compounds highly susceptible to auto-oxidation in the presence of oxygen in air. This oxidation results in polymerization of monomers such as flavonoid monomers to give polymers of high molecular weights. It was demonstrated that the mechanism of toxicity against microorganisms was done either by the deprivation of metal ions such as iron or by non-specific interactions such as the establishment of hydrogen bridges with the proteins of the cell membranes (Adhesins) or enzymes [24,25].

The determination of the MIC of different extracts enabled us to compare the efficacy of polyphenolic extracts against MRSA. The minimum inhibitory concentration has an inversely proportional relationship with the antibacterial effect. Thus, more than MIC was low, inhibitory activity was important [26]. The polyphenolic extract of Jijel has the highest inhibitory effect among all extracts with the MIC of $0.095 \mu \mathrm{l} / \mathrm{ml}$. It was noticed that the extract of Oran, Tlemcen and Mascara were presented a value of MIC of 1.1, 1.2 and $1.4 \mu \mathrm{l} / \mathrm{ml}$ respectively.

\section{Conclusion}

In this study, we investigated the antibacterial effect of polyphenolic extract from honey. The polyphenolic extract honey of Jijel has the lowest inhibitory concentration and therefore having the highest inhibitory activity against Methicillin Resistant Staphylococcus aureus. This effect was related to the composition of honey in bioactive compounds. Regular consumption of honey is a very good attitude because it is a great source of energy, trace elements, and vitamins. International studies are now confirming what the ancients already knew.

\section{Acknowledgements}

Authors are thankful to all staff of the Directorate of Education of the Mascara University.

\section{Conflict of Interest}

The Authors declare that there is no conflict of interest.

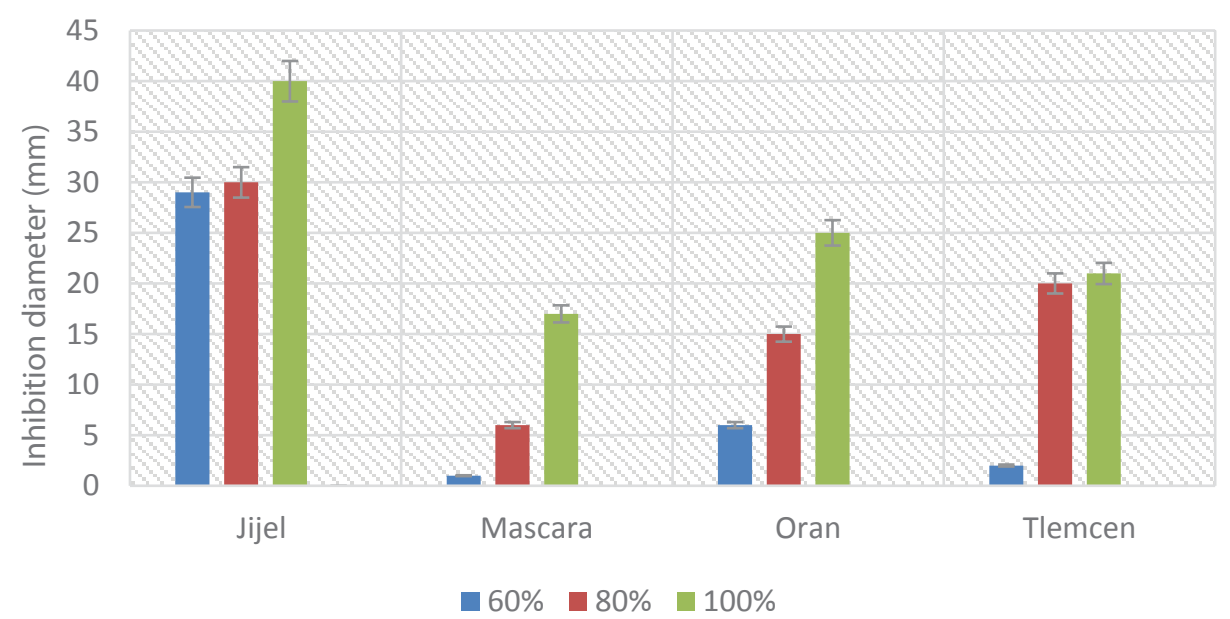

Figure 3. Antibacterial activity of polyphenolic extracts honey against MRSA. 
- Background: Methicillin resistant Staphylococcus aureus present multiple problems of nosocomial infectious diseases, in addition to the multidrug resistance. Our work aims to evaluate the antibacterial effect of four polyphenolic extracts from honey against Methicillin resistant Staphylococcus aureus. Methods and findings: An extraction of polyphenol was carried out from different honey samples collected from different sites of the Algerian territory. Then, the study of the antibacterial effect was performed by the determination of inhibition diameter and the minimal inhibitory concentration. The results indicated that the extracts of honey presented different total phenolic content with high value of $76 \pm 1.1 \mathrm{mg} \mathrm{GAE} / 100 \mathrm{~g}$ of fresh weight. It was clearly showed the sensitivity of MRSA against polyphenolic extracts. This inhibitory effect was found for the four samples tested with varying degrees of inhibition. The polyphenolic extract of Jijel has the highest inhibitory effect among all extracts with the MIC of $0.095 \mu \mathrm{l} / \mathrm{ml}$. Conclusion: The study of the antibacterial effect of honey extracts allowed us to present an alternative way against the infectious diseases.

\section{References}

1. Lowy FD. Staphylococcus aureus infections. N. Eng. J. Med. 339(8): 520-532 (1998).

2. Mandell Gerald L, Dolin R, Bennett John E. Principles and practices of infectious disease, 7 th edition. Churchill Livingstone, Philadelphia, Pennsylvania, USA, 1754-1777 (2010).

3. Aklilu E, Zunita Z, Hassan L. Phenotypic and genotypic characterization of methicillin-resistant Staphylococcus aureus (MRSA) isolated from dogs and cats at University Veterinary Hospital, University Putra Malaysia. Tropic. Biomed. 27(3): 483-492 (2010)

4. Rayner C, Munckhof WJ. Antibiotics currently used in the treatment of infections caused by Staphylococcus aureus. Int. Med. J. 35(2): 3-16 (2005).

5. Denisow B, Denisow-Pietrzyk M. Biological and therapeutic properties of bee pollen: A review. J. Sci. Food. Agri. (2016).

6. Muhammad A, Odunola OA, Ibrahim MA, et al. Potential biological activity of acacia honey. Frontiers in Bioscience. (Elite Ed), 8, pp. 351-357 (2016).

7. Effem S. Clinical observations on the wound healing properties of honey. Br. J. Surg. 75(7): 679-681 (1988).

8. Alvarez-Suarez JM, Tulipani S, Romandini S. Contribution of honey in nutrition and human health: a review. Mediterr. J. Nutri. Metabol. 3(1): 15-23 (2010).

9. Irish J, Blair S, Carter DA. The antibacterial activity of honey derived from Australian flora. PLoS ONE. 6(3): e18229 (2011).

10. Hegazi Ahmed G. Antimicrobial activity of different Egyptian honeys as comparison of Saudi Arabian honey. Res. J. Microbiol. 6(5): 488-495 (2011).

11. Sekou D, Kouakou EK, Désiré A, Ouolo C, Hubert DF. Performance of two techniques for extracting phenols root for the evaluation of the marking tolerance to Fusarium wilt of Oil palm clones (Elaeis guineensis Jacq.). Sci. Nat. 6(2): 117-123 (2009).

12. Socha R, Juszczak L, Pietrzyk S, Gałkowska D, Fortuna T, Witczak T. Phenolic profile and antioxidant properties of Polish honeys. Int. J. Food. Sci. Technol. 46: 528-534 (2011).

13. Hamoudi R. Contribution to the identification of active principles of plant Teuriumpolium geryrii from the Tamanrasset region. Magister thesis, University of kasdi merbah, Ouargla, Algeria (2008).

14. Moreda R. Antibiogramm, context and technique. High School Dr. Lacroix - Narbonne, France (2009).

15. Al ML, Daniel D, Moise A, Bobis O, Laslo L, Bogdanov S. Physicochemical and bioactive properties of different floral origin honeys from Romania. Food. Chem. 112: 863-867 (2009).

16. Gomes S, Dias LG, Moreira LL, Rodrigues P, Estevinho L. Physicochemical, microbiological and antimicrobial properties of commercial honeys from Portugal. Food. Chem. Toxicol. 48: 544-548 (2010).

17. Zujko ME, Witkowska AM, Łapin' ska A. Włas'ciwos'ci antyoksydacyjne miodów pszczelich. Bromatologia i Chemia Toksykologiczna. 38: 7-11 (2005).

18. Harris R, Karmas E. Nutritional evaluation of food processing, The Avi Publishing Company, Inc., Westport, Connecticut, USA, 670 (1977).

19. Macheix JJ, Fleuriet A, Billot J. Fruits phenolics. CRC Press, Inc., Boca. Raton, 392 (1990).

20. Amiot MJ, Tacchini M, Aubert SY. Influence of cultivar, maturity stage, and storage condition on phenolic composition and enzymatic browning of pear fruits. J. Agri. Food. Chem. 43(5): 1132-1137 (1995).

21. Pereira JA, Pereira APG, Ferreira ICFR, Valentão P, Andrade $\mathrm{PB}$, Seabra R, et al. Table olives from Portugal: compounds, antioxidant potential, and antimicrobial activity. J. Agri. Food. Chem. 54: 8425-8431 (2006).

22. Estevinho L, Prereira AP, Moreira L, Dias LG, Pereira E. Antioxidant and antimicrobial effects of phenolic compounds extracts of Northeast Portugal honey. Food. Chem. Toxicol. 46: 3774-3779 (2008)

23. Agbaje EO, Ogunsanya T, Aiwerioba OIR. Conventional use of honey as antibacterial agent. Ann. Afr. Med. 5: 79-81 (2006).

24. Scalbert A. Antimicrobial properties of tannin. Phytochemistry. 30: 3875-3883 (1991).

25. Cowan MM. Plant products as antimicrobial agents. Clin. Microbiol. Rev. 564-582 (1999).

26. Freney J, Husson MO, Gavini F. Susceptibilities to antibiotics and antiseptics of new species of the family Enterobacteriaceae. Antimicrob. Agents. Chemother. 32:873-876 (1988). 